\title{
Squeeze Casting of Sic,Fly-Ash Reinforced Aluminium Alloy Hybrid Composites-A Review
}

\author{
MaraparambilRamachandran $^{a}$, Dr.K.Thirunavukkarasu ${ }^{b}$, Dr.V.R. Pramod ${ }^{c}$ \\ ${ }^{a}$ Research Scholar, Karpagam Academy of Higher Education, Coimbatore, Tamilnadu,India \\ ${ }^{\mathrm{b}}$ Professor, Department of Mechanical Engineering, Karpagam Academy of Higher Education, Coimbatore, Tamil Nadu, India \\ ${ }^{c}$ Professor, Department of Mechanical Engineering, NSS College of Engineering, Palakkad, Kerala,India

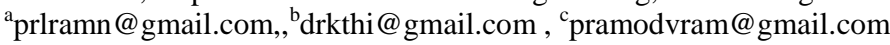

Article History: Received: 10 November 2020; Revised 12 January 2021 Accepted: 27 January 2021; Published online: 5 April 2021

\begin{abstract}
Aluminum alloys reinforced composite materials have been widely used in automobile, aeronautical and other commercial applications. Aluminum composites are light weight material with high specific strength, specific modulus, stiffness, heat resistant,eco-friendly and have extreme properties so used in large volumes. Due to these circumstances;we have to reduce the price and weight of the composites, improve and increase physical and mechanical properties. One of the ways to reduce the cost of composites is reducing the cost of reinforcement by using cheap, weightless, and easily available materials like fly ash and improving the properties by adding sic. These properties are achieved through the properties intrinsic in them and the size, shape, orientation, weight and distribution.

Several casting methods are used by the industries to manufacture the composite products, and each casting method has its own pros and cons. In traditional process, defects of pore formation due to gas, shrinkage porosities are regular and these defects decrease the mechanical properties and integrity of the end product. To overcome such defects,comparatively better squeeze casting method can be implemented.
\end{abstract}

Keywords: Aluminum Matrix composites, Fly ash, Silicon carbide, Squeeze casting

\section{Introduction}

Metal matrix composites are the very advanced among all classes of composites and are metal dispersing the reinforced.Reinforcements give specific strength, specific modulus, stiffness, heat resistance and environmental friendlyTensile strength, strain, hardness, wear are also increased.

Aluminum alloys have been an attractive choice as base metal and effective due to their good properties. It has reduced the weight, increased composites life and improved recyclability so that it is widely used in industries. Cost is the key factor for the wider use and is still more expensive. Cost can be reduced by advanced fabrication technique, better production rate and by cheap filler materials. Fly ash is the cheapest which is available in bulk ${ }^{5-9}$.

Silicon Carbide (Sic), Aluminum Oxide $\left(\mathrm{Al}_{2} \mathrm{O}_{3}\right)$, Titanium carbide (Tic), boron carbide $\left(\mathrm{B}_{4} \mathrm{C}\right)$, Zircon, graphite, natural minerals and fly ash should be stable and non-reactive in working temperature are the common reinforcements ${ }^{10-14}$. Considering the increase in sic reinforcement ratio, tensile strength, hardness, density, wear resistance can be increased and reduced impact toughness is also achieved ${ }^{15-17}$. Sic aluminum metal matrix composites (AlMMCs) shows higher wear resistance than $\mathrm{Al}_{2} \mathrm{O}_{3}$ reinforced and best for brake drums ${ }^{18-20}$. The $\mathrm{Al}_{2} \mathrm{O}_{3}$ reinforcement gives good compressive strength and wear resistance and reduces fracture toughness. Boron Carbide $\left(\mathrm{B}_{4} \mathrm{C}\right)$ increases the hardness and wear resistance ${ }^{21-24}$.Zircon is hybrid reinforcement;increases wear resistance and compressive strength of $\mathrm{MMCs}^{25-28}$. MMCs with diamond fiber yields high thermal conductivity and low thermal expansion coefficient ${ }^{29-30}$. Graphite is a hybrid reinforcement, particle which improves lubrication and reduces friction coefficient and wear ${ }^{31-34}$ When the particle size of graphite is bigger, the wear of composite is smaller, and vice versa.

Fly ash, potential reinforcement for aluminum based alloys ${ }^{35-39}$. The use it recently enhanced due to their low density and is available in bulk. Precipitator (solid particle) and cenosphere (hollow particles) types are available ${ }^{40-42}$. Fly ash increases the electromagnetic shielding effect of the AlMMC ${ }^{43}$. Fly ash particulate reduces tensile strength and the wear resistance of AlMMC ${ }^{44}$.The corrosion resistance of AlMMC is found to be reduced due to enriched fly ash content $\frac{45}{}$. Addition to this filler decreases coefficient of thermal expansion of aluminum alloys; porosity levels should be minimum, improves wear resistance ${ }^{46}$. The manufacturing of MMCs by casting is very popular as it is relatively cheap. Liquid Metallurgy Squeeze casting technique is characterized by fine micro structure. Stir casting and squeeze casting are generally used fabricating technique for fly ash reinforced $\mathrm{Al}$ metal 
matrix composites $\underline{47-53}$

\section{Advantages of squeeze casted aluminum alloys}

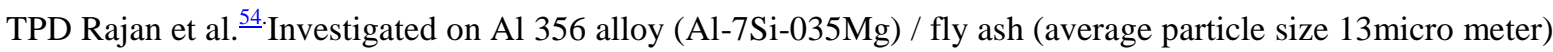
composite using various processes. Fly ash used has its density is $2.486 \mathrm{~g} / \mathrm{cc}$. They found out that squeeze casting gives relatively better porous free fly ash particle dispersed composites. Squeeze casting is better than any other casting techniques.

Surface treated fly ash particles give less porosity effectively. Squeeze casting gives best distribution of fly ash compared to compo casting and stir casting. Interfacial reaction between the filler and the matrix are more in stir casting composite than in compo casting which depends on type of filler. The compressive strength of modified compo casting cumsqueeze casted Al-fly ash composite increased, tensile strength reduced.

R.Escalera-Lozano et al. ${ }^{55}$ Experimentally evaluated corrosion characteristics of composites made from Sic, fly ash and recycled aluminium. It is found that micro anode developed with the matrix led to localized corrosion. Besides $\mathrm{SiO}_{2}$ in fly ash prevents the adverse effect of Sic with liquid aluminum, chemical dilution happens due to formation of $\mathrm{Al}_{4} \mathrm{C}_{3}$ with aluminum and carbon. The carbon's unavailabilityand the existence of $\mathrm{SiO}_{2}$ avoides chemical degradation by $\mathrm{Al}_{4} \mathrm{C}_{3}$ hydrolysis. In this way it will become stable, even in humid atmosphere so that composites can be prepared.

W. A. Uju et al. ${ }^{56}$ Carried out the study on CTE of stir casted A535, sic and fly ash reinforced composite. The reinforcements used were casted with A535 and then fabricated by stir casting showed the decrease in CTE with the presence of fly ash and Sic particles.

Anilkumar H.C et al. ${ }^{57}$ Conducted investigation on the influence of fly ash particle size in 6061 composites, processed by stir casting using three set of material composition with filler material powder size range of 4-25 $\mu \mathrm{m}$, $45-50 \mu \mathrm{m}$ and 75-100 $\mu \mathrm{m}$. Every set involves three kinds of composition samples having weight percentages of 10, 15 and 20\%, it is found that the mechanical behaviour of $\mathrm{Al} 6061$ composites decreases due to higher particle size of filler materials. Study has found that fly ash composite material is better for tribological uses.

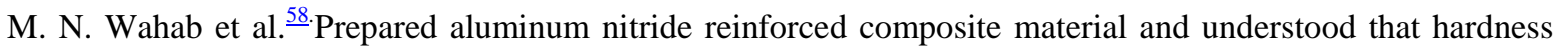
value is increased with composite reinforced with $5 \mathrm{wt}$. \% aluminum nitride powder. The wear resistance has enhanced due to higher fly ash, but reduces with rise in normal load. The Tensile and Compressive Strength are improved. Hardness enhanced and ductility of composite is decreased with increase in the percentages of reinforced filler and Tensile Strength, Compression strength, Hardness and ductility reduced with higher particle size of the filler.

G.N.Lokesh et al. ${ }^{59}$ Studied on characterizations of squeeze casted composite from Al- Cu alloy and flyash. Liquid metallurgy squeeze casting method results in fine micro structure. The percentage of fly ash increases porosity. Micro structure of composite showed better squeeze casting.

SEM shows good bonding between filler and matrix. Impact strength improved for higher percentage of fly ash. Fly ash with $12 \mathrm{wt} \%$ reveal lesser porosity than gravity cast and higher compression strength. $\mathrm{Al}-4.5 \mathrm{wt} \% \mathrm{Cu}$ alloy and fly ash composite can be used for rolling applications.

K.S.Sreenivasan et al. ${ }^{60}$ Fabricated and tested Al-Sic composite and Al-Sic, Fly Ash hybrid used microwave sintering powder metallurgy method. The aluminum(44 micron),Sic(37 micron) and Fly ash(20 micron) were used in the study. 5, 10,15and $20 \%$ of Sic was used to fabricate composite and $20 \%$ of SiC-10\% Flyash were used to process hybrid composite of aluminum, Sic and fly ash. Compacting load between 4000kg to $8000 \mathrm{~kg}$ were used in making the composite. Microwave furnace sintering temperature was $600^{\circ} \mathrm{C}$ for one hour duration. Hardness value of $81 \mathrm{HRB}$ (Rockwell B-scale) was obtained in Al-20\%SiC-10\% fly ash composite corresponding to the $8000 \mathrm{~kg}$ load. Higher Percentage of Silicon carbide yield higher hardness. Maximum densification of $96 \%$ under compacting load of $8000 \mathrm{~kg}$ were obtained. Uniform distributed Silicon carbide and fly ash in the aluminum were possible in the fabrication of hybrid composite than the manual mixing of powders and magnetic mixing of powders yields better hardness.

L.Zhang et al. ${ }^{61}$ Prepared composites with aluminum as matrix materials and sic as strengthening materials. So easy to produce and have high stiffness. They found that aluminum/Sic composites possessed better corrosion resistance than pure aluminum matrix.

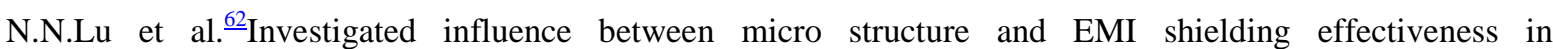
AZ91 magnesium composite(FACs/AZ91 and M-FACs/AZ91) made by stir casting using raw FACs which was severely broken and $\mathrm{Ca}(\mathrm{OH})_{2}$ modified FACs , majority which completely in the composites and were distributed effectively in the matrix found that raw FACs did not enhance the EMI shielding effect, but the modified FACs enhanced the electromagnetic shielding effect. 
G.Narasaraj el at. ${ }^{63}$ Compared the mechanical properties of 6061 Aluminium Alloy $+10 \%$ Rice husk $+10 \%$ Fly ash composite to as-cast alloy without reinforcement. Rice husk and fly ash are characterized by high hardness and have improved properties.It can be considered as an alternative to Sic and $\mathrm{Al}_{2} \mathrm{O}_{3}$.

\section{Conclusions}

Various research activities and work related to reduce the price and weight of aluminum composites at the same time improving mechanical properties and micro structure are discussed here. Various processing of MMCs also described here. Inclusion of silicon carbide improves the mechanical properties of composites. Inclusion of fly ash helps to reduce weight cost and also improves the properties. Usage of fly ash will reduce environmental problems by effective managing of waste from power plant and energy and money are saved. Among various processing technique squeeze casting gives better properties and also reduces porosity, reduces wastages of raw materials

\section{References}

J. Kumar, D. Singh, N. S. Kalsi, S. Sharma, C. I. Pruncu, D. Y. Pimenov, K. V. Rao and W. Kapłonek, Journal of Materials Research and Technol

B. Suresh Babu, P. Prathap, T. Balaji, D. Gowtham, S. D. Sreeogy 9 (6), 13607-13615 (2020).Adi, R. Divakar and S. Ravichandran, Materials Today: Proceedings (2020).

S. R. Mungara, H. S. Manohar and M. A. Trishul, Materials Today: Proceedings (2020).

S. Sharma and S. P. Dwivedi, Journal of Hazardous Materials 333, 1-9 (2017).

S. V. Prasad and R. Asthana, Tribology Letters 17 (3), 445-453 (2004).

M. Rosso, Journal of Materials Processing Technology 175 (1), 364-375 (2006).

N. Chawla and Y.-L. Shen, Advanced Engineering Materials 3 (6), 357-370 (2001).

S. C. Tjong and Z. Y. Ma, Materials Science and Engineering: R: Reports 29 (3), 49-113 (2000).

D. B. Miracle, Composites Science and Technology 65 (15), 2526-2540 (2005).

P. Ajagol, B. N. Anjan, R. N. Marigoudar and G. V. Preetham Kumar, IOP Conference Series: Materials Science and Engineering 376, 012057 (2018).

G. Straffelini, F. Bonollo, A. Molinari and A. Tiziani, Wear 211 (2), 192-197 (1997).

S. Tomida, K. Nakata, S. Saji and T. Kubo, Surface and Coatings Technology 142-144, 585-589 (2001).

V. M. Ravindranath, G. S. Shiva Shankar, S. Basavarajappa and N. G. Siddesh Kumar, Materials Today: Proceedings 4 (10), 11163-11167 (2017).

H. Abdizadeh, M. Ashuri, P. T. Moghadam, A. Nouribahadory and H. R. Baharvandi, Materials \& Design 32 (8), 4417-4423 (2011).

T. Ye, Y. Xu and J. Ren, Materials Science and Engineering: A 753, 146-155 (2019).

V. Balaji, N. Sateesh and M. M. Hussain, Materials Today: Proceedings 2 (4), 3403-3408 (2015).

S. K. Ghosh and P. Saha, Materials \& Design 32 (1), 139-145 (2011).

A. Rehman, S. Das and G. Dixit, Tribology International 51, 36-41 (2012).

S. P, H. K. Natarajan and P. K. J, The International Journal of Advanced Manufacturing Technology 94 (1), 1461-1475 (2018).

M. Kumar, M. M. A, V. Baskaran and K. S. H. Ramji, Proceedings of the Institution of Mechanical Engineers, Part J: Journal of Engineering Tribology 230 (4), 402-415 (2015).

C. Wu, G. Luo, J. Zhang, Q. Shen, Z. Gan, J. Liu and L. Zhang, Powder Technology 339, 809-816 (2018).

B. VijayaRamnath, C. Elanchezhian, M. Jaivignesh, S. Rajesh, C. Parswajinan and A. Siddique Ahmed Ghias, Materials \& Design 58, 332-338 (2014).

K. T. Akhil, J. Varghese, A. Raphel, K. Vinoj and F. K. Francis, Materials Today: Proceedings 4 (8), $7202-7207$ (2017).

K. Gurusami, S. Shalini and T. Sathish, Materials Today: Proceedings (2020).

S. Kumar Patel, R. Nateriya, B. Kuriachen and V. Pratap Singh, Materials Today: Proceedings 5 (9, Part 3), 19790-19798 (2018).

V. Mohanavel, M. Ravichandran and S. Suresh Kumar, Materials Today: Proceedings 21, 862-864 (2020).

R. Srinivasan, B. HemanthShrinivasan, K. JeevanPrasath, R. Johnson Saleth and R. D. Anandhan, Materials Today: Proceedings 27, 1821-1826 (2020).

V. Boobesh Nathan, R. Soundararajan, C. Brainard Abraham, E. Vinoth and J. K. Narayanan, Materials Today: Proceedings (2020).

W. B. Johnson and B. Sonuparlak, Journal of Materials Research 8 (5), 1169-1173 (1993).

J. Shi, R. C. Che, C. Y. Liang, Y. Cui, S. B. Xu and L. Zhang, Composites Part B: Engineering 42 (6), $1346-$ 1349 (2011).

T. Satyanarayana, P. S. Rao and M. G. Krishna, Heliyon 5 (6), e01770 (2019).

P. Sundriyal and P. L. Sah, Materials Today: Proceedings 4 (9), 9481-9486 (2017). 
S. N. Alam and L. Kumar, Materials Science and Engineering: A 667, 16-32 (2016).

M. Saravanan, R. M. Pillai, K. R. Ravi, B. C. Pai and M. Brahmakumar, Composites Science and Technology 67 (6), 1275-1279 (2007).

P. Mhamane, S. Kadam, V. Phanse and S. B. Bhosale, Materials Today: Proceedings 24, 2302-2308 (2020).

A. Patil, N. R. Banapurmath, A. M. Hunashyal and S. Hallad, Materials Today: Proceedings 24, 1654-1659 (2020).

N. Sathishkumar, K. Pravinkumar, G. AshwinPrabhu, M. Siva and P. L. Sudharsan, Materials Today: Proceedings (2020).

R. Devanathan, J. Ravikumar, S. Boopathi, D. Christopher Selvam and S. A. Anicia, Materials Today: Proceedings 22, 3136-3144 (2020).

I. Dinaharan and E. T. Akinlabi, Composites Communications 9, 22-26 (2018).

X. Querol, A. Alastuey, A. Lopez-Soler, E. Mantilla and F. Plana, Atmospheric Environment 30 (21), 3557-3572 (1996).

G. L. Fisher, D. P. Y. Chang and M. Brummer, Science 192 (4239), 553 (1976).

C. A. J. Paulson and A. R. Ramsden, Atmospheric Environment (1967) 4 (2), 175-185 (1970).

Z. Dou, G. Wu, X. Huang, D. Sun and L. Jiang, Composites Part A: Applied Science and Manufacturing 38 (1), 186-191 (2007).

B. R. Reddy and C. Srinivas, Materials Today: Proceedings 5 (2, Part 2), 8374-8381 (2018).

E. Marin, M. Lekka, F. Andreatta, L. Fedrizzi, G. Itskos, A. Moutsatsou, N. Koukouzas and N. Kouloumbi, Materials Characterization 69, 16-30 (2012).

P. K. Rohatgi, N. Gupta and S. Alaraj, Journal of Composite Materials 40 (13), 1163-1174 (2005).

J. Vairamuthu, B. Stalin, G. D. Sivakumar, B. MohmedFazil, R. Balaji and V. AnandaNatarajan, Materials Today: Proceedings (2020).

T. Tamilanban and T. S. Ravikumar, Materials Today: Proceedings (2020).

A. S. Negi and T. Shanmugasundaram, Materials Today: Proceedings (2020).

A. Karthik, R. Karunanithi, S. A. Srinivasan and M. Prashanth, Materials Today: Proceedings 27, 2556-2561 (2020).

J. H. Gerard, Materials \& Design 5 (2), 59-65 (1984).

J. V. Christy, R. Arunachalam, A.-H. I. Mourad, P. K. Krishnan, S. Piya and M. Al-Maharbi, Journal of Manufacturing Processes 59, 287-301 (2020).

G. Chen, M. Yang, Y. Jin, H. Zhang, F. Han, Q. Chen and Z. Zhao, Journal of Materials Processing Technology 266, 19-25 (2019).

T. P. D. Rajan, R. M. Pillai, B. C. Pai, K. G. Satyanarayana and P. K. Rohatgi, Composites Science and Technology 67 (15), 3369-3377 (2007).

R. Escalera-Lozano, C. A. Gutiérrez, M. A. Pech-Canul and M. I. Pech-Canul, Materials Characterization 58 (10), 953-960 (2007).

W. A. Uju and I. N. A. Oguocha, Materials \& Design 33, 503-509 (2012).

H. C. Anilkumar and H. S. Hebbar, International Journal of Mechanic Systems Engineering 3 (1), 6-13 (2013).

M. N. Wahab, A. R. Daud and M. J. Ghazali, International Journal of Mechanical and Materials Engineering 4 (2), 115-117 (2009).

G. N. Lokesh, M. Ramachandra, K. V. Mahendra and T. Sreenith, MultiCraftInternational Journal of Engineering, Science and Technology 5 (4), 71-79 (2013).

K. S. Sreenivasan, S. Kathiresan and C. Nandakumar, IOSR Journal of Mechanical and Civil Engineering 1 (1), 54-65 (2014).

L. Zhang, H. Xu, Z. Wang, Q. Li and J. Wu, Journal of Alloys and Compounds 678, 23-30 (2016).

N. N. Lu, X. J. Wang, L. L. Meng, C. Ding, W. Q. Liu, H. L. Shi, X. S. Hu and K. Wu, Journal of Alloys and Compounds 650, 871-877 (2015).

G. Narasaraju and D. L. Raju, Materials Today: Proceedings 2 (4), 3056-3064 (2015). 